\title{
Discussion on Strengthening Enterprise Financial Management
}

\author{
Hairong Li \\ School of economics and management, Xi'an Aeronautical University, Xi'an 710077, China
}

\begin{abstract}
Keywords: Business management, Financial management, Fine, Financial management.
\end{abstract}
\begin{abstract}
Financial management plays an important role in enterprise content management, and financial management activities should not be limited to internal corporate finance departments, and financial management should be thinking penetrated into all aspects of everyday business management activities. The market increasingly competitive, companies have to survive and development, we must enhance their market competitiveness, financial management plays a vital role in enhancing the competitiveness of enterprises in the process of implementation of sophisticated financial management can greatly enhance competitiveness in the market, while enhancing the ability of enterprises to avoid risks, contribute to long-term development.
\end{abstract}

\section{Introduction}

Financial management as an important basis for enterprise survival and development, financial management work smoothly only can maintain the daily business activities of enterprises and for enterprises to maximize economic benefits, but also greatly enhance the enterprises in the same industry market competitiveness. Although the importance of the current financial management of the majority of business managers recognized, but they lack the financial and scientific management ideas, they still insist on using traditional financial management to manage modern financial management activities, and not for the enterprise zone to tangible economic benefits, but not fully exploited the financial management activities to enhance their market competitiveness, on the contrary, this approach enterprise managers will greatly hamper enterprises in the fierce market environment in the longer term development opportunities.

\section{Situation of financial management in business operations}

\section{Capital expenditure is out of balance.}

Profit is the fundamental purpose of business activities, is the basis of survival and development, business investment activity mainly carried out by the funds used to obtain more money in return activities. During the actual business activities of enterprises, the rate of recovery of funds is not the same, and some capital recovery rate can quickly recover in the short term, but some funds will need a long payback period to recover, because the investment the process, due to the time value of money with a possible appreciation, inflation and other factors but there is impairment of funds, so the longer the payback period, the risk of impairment of capital for businesses facing greater. Cash flows as part of financial management in the daily business activities of enterprises have a decisive role in the success or failure of the enterprise, many companies are due to improper management of cash flow of enterprise funds strand breaks, leading to bankruptcy, so companies should be in the course of business activities strengthen cash flow management, to ensure their liquidity smoothly, provide strong support for the development of enterprises.

\section{Capital structure is unreasonable.}

Capital structure refers to the ratio between the value of the structure and configuration of the various business capital, it is a result of business combination to raise a certain period. Capital structure, including debt capital and equity capital structure, long-term capital and short-term capital structure, the internal structure of debt capital, the internal structure of the internal structure of long-term capital and equity capital, should be maintained at an appropriate capital structure between different ratio within the range of, if unreasonable capital structure will result in business funds cannot fully play the role of creating enterprise value, but the current capital structure of many 
companies there are unreasonable, some business cash flow difficulties, some cash on excessive and wasteful loss of funds, which are the corporate capital structure is irrational performance.

\section{Business capital turnover is difficult.}

Corporate cash flow the company's ability to show profitability, cash flow represents the completion of a business completed a profit-making activities, the more times cash flow, business interests harvested the higher, and with the capital turnover rate increase in fixed asset utilization efficiency of enterprises will also be improved, which can reduce the cost per unit of product, which helps enterprises to form a price advantage and enhance market competitiveness for enterprises to develop a broader market sales, once the sales market expand, then we will increase the turnover rate of enterprise funds, and so on ad infinitum making ability of enterprises to survive and develop stronger. If the cash flow difficulties of enterprises, enterprises will face the risk of bankruptcy, many enterprises are cash flow there is a certain problem.

Fund withdrawal is threatening the survival of the enterprise.

Shareholders will inject their own funds into the enterprise has obtained the ownership interest, their purpose is to hope that their invested capital to earn more benefits from their own interests, they require companies to follow at the end of a certain the proportion of shareholders' dividends. When companies get the profits, but also taking into account the future development of enterprises on the basis of the time there are funds remaining to distribute the profits it is conducive to enterprise development, but if the enterprise funds have been insufficient or future project needs a better investment when money, we shift their current profits allocated, it will hinder the further development of enterprises [1].

\section{Further exploration of enterprise financial management}

\section{Financial management functions.}

The company's financial management is the organization's financial activities to address an economic activity financial relationship, specifically refers to the companies to raise capital, investments, turnover and profit distribution of economic activities in working capital management. The fundamental purpose of business is to obtain maximum economic benefits, earn more profits for the company, the financial sector occupies a dominant value in its enterprise management, enterprise economic benefits will ultimately be reflected by the company's financial reporting, financial management activities of daily business activities of enterprises should carry out a full range of budgets and control, with minimum waste and maximum economic efficiency of enterprises. Survival and financial management development and business enterprises are closely linked, but the current level of financial management of many enterprises is relatively low, the way financial management is relatively backward, but also a lack of scientific financial thinking as a guide, hindering financial management level improved. Modern Financial contains accounting and financial management enterprise two aspects of financial management and accounting is a clear distinction, accounting focuses on corporate finance and accounting profit, the main activities account, afterwards, accounting and other static affairs, but is not limited to only financial management accounting, afterwards, accounting and other static affairs, but also for corporate funds, assets, costs, and other aspects of risk management activities. From the time point of view of both concern, accounting for the past focused primarily on financial accounting, financial management and accounting of the past not only financial, but also on the current financial situation is controlled, even for the future financial and budget planning financial management of enterprises to improve efficiency, capacity and cost control of enterprise risk aversion plays a significant role in guiding and monitoring. Therefore, in the modern enterprise management, we should pay attention to the financial management activities of the enterprise, and constantly improve the quality of corporate financial management procedures and work to improve the authenticity of the financial information, reduce business activity in the process of financial risk, improve corporate management level and market competitiveness. 


\section{Enhance the comprehensive capacity of financial officers, financial management culture consciousness of non-financial personnel.}

The development of modern enterprises should focus on the corporate finance team to train and construct the one hand to strengthen the cultivation of ideological and moral qualities and intellectual ability of corporate financial accounting personnel, accounting personnel to strengthen the professional responsibility and strict pragmatic work attitude; another On the one hand but also focus on capacity-building in all aspects of accounting personnel, improve the overall quality of accounting personnel, accounting personnel to fully understand the business of production operations and current financial situation in which so deeply rooted sense of financial management, financial accounting, the company should the actual situation of the company is based, to strengthen the financial accounting information authenticity, reliability and timeliness. Should also be driven by the staff involved in financial management, financial management awareness so deeply the hearts of the entire staff, and thus play a role in promoting better financial management of the company's development [2].

\section{Strengthen financial management, the implementation of sophisticated management and control measures.}

Financial management functions with the fierce market competition and rapid changes in the external environment changes gradually, enterprises in order to adapt to the inevitable choice of the times should continue to strengthen the level of financial management and implementation of sophisticated financial management. Implementation of sophisticated financial management can greatly stimulate the potential development of enterprises; improve the efficiency in the use of corporate funds, to create huge economic benefits for the enterprise.

1) Strengthen the system construction, to protect fine financial management implementation

Enterprise is the enterprise system construction management activities together with the basis and foundation for the implementation of sophisticated financial management enterprise system is inseparable from the support and security, the development of enterprises need a sound institutional system to regulate the details of financial management, through developed in line with the actual situation of enterprises and the practical management in place to standardize work processes, so that each of the specific work to follow, according to the enterprise has to follow. Through sound enterprise management system, detailed job responsibilities of each enterprise, while establishing refinement and practical work of regulatory and supervisory system, providing strong support for the enterprise implementation of a comprehensive refinement of financial management.

2) The penetration of financial management thinking into every aspect of business activities

Fine focus on the financial management of enterprises and the entire process of comprehensive management of the modern enterprise management concept should not be limited to financial management among the financial sector, but should be extended to the awareness of financial management in all areas of business management, the contents of the financial management of refinement to the various business sectors, and enhance horizontal coordination in the financial sector and other business sectors, but also to establish the appropriate regulatory and supervisory mechanisms for each job and each enterprise specific work. While for the enterprises should strengthen the management of accounting, for the previous financial management functions are static accounting afterwards, the whole process of modern enterprises should strengthen financial management, a full range of dynamic control, and establish a budget in advance, and control and supervision of the entire post the process of financial management system. In the course of daily business activities of enterprises should actively encourage all employees to participate in financial management process for enterprises to achieve the goal and gathering strength, enhance their market competitiveness.

3) Optimize financial management, financial management, information technology to promote

Financial management thoughts and actions to penetrate into all areas of the business process and links to real-time information so that enterprises of the collection, collation and analysis has become very difficult to solve this problem have to take advantage of modern information technology, to promote the strengthening of corporate finance information technology management, providing important technical support for the implementation of sophisticated enterprise financial management 
activities. In today's information age, modern information technology in enterprises use more widely, to strengthen corporate financial management, information technology can provide decision makers with comprehensive, timely and accurate financial information, you can also save labor costs of enterprises while improving the efficiency of data processing. Through the construction of information, companies can improve the efficiency of daily work for the enterprise implementation of financial management of refinement to provide a guarantee.

4) Implementation of fine financial management content

Through the promotion of corporate financial management, information technology, financial management of enterprises to provide a content of fine premise. Enterprise management as a breakthrough in financial management, through the regulation of daily cash flow from operating activities in the various departments to increase efforts to control every aspect and to make use of resources and production of organic combine to achieve the financial management of the enterprise full participation in every aspect. Refinement of financial management enterprise content requires financial information to a data analysis and data management, financial analysis content will be deep into all aspects of production and operation process, making financial and operating two aspects can be organically combined. Through corporate meticulous financial management tools, companies can focus on the business activities of close supervision, analysis of information and data that the operational activities of the enterprise managers to provide timely and accurate data on the status of the business, to provide strong support for business decisions. Businesses often use financial analysis to assess the financial position and operating performance measure, but we should tap the potential value inherent in the financial analysis, used to accurately predict the company's future. Market economy continues to improve corporate financial management functions make gradual changes, companies must adopt a positive attitude to face these changes, financial management is the most basic business management enterprise management, the implementation of sophisticated financial management can reduce losses, improve business economic benefits, but also can avoid the business risk to a certain extent, enhance their market competitiveness, and thus strengthen the financial management of the core position in enterprise management for the survival and development has a crucial role [3].

\section{Conclusions}

In summary, in recent years, China's market economic system reform to promote the rapid development of SMEs, small and medium enterprises occupy an increasingly important role in our national economy, promote the rapid development of social economy. At present, many small and medium enterprises operating in the process faced many challenges, although the state of development of SMEs provides a number of policy support, but because of the smaller, less capital and market competition incentives reason SMEs, making enterprises faced with the threat of survival. Strengthen financial management of daily operations and contribute to the steady development of enterprises, small and medium enterprises out of the current predicament has a positive role in promoting.

\section{References}

[1] Yang Yinghui. On Strengthening Financial Accounting Management, Times Finance, 2012,03:36.

[2] Sun Tiecheng. Several Issues on Strengthening the Financial Management of Enterprises, Zhejiang vocational technical institute of Industry and Commerce Journal,2013,02:22-26.

[3] Wang Ling. Strengthening Enterprise Accounting Financial Management Discussion, Modern economic information,2013,17:301. 